\title{
THE DESTRUCTION OF GLUCAGON, ADRENOCORTICOTROPIN AND SOMATOTROPIN BY HUMAN BLOOD PLASMA*
}

\author{
By I. ARTHUR MIRSKY, GLADYS PERISUTTI, AND NEIL C. DAVIS \\ (From the Department of Clinical Science, University of Pittsburgh, School of Medicine, \\ Pittsburgh, Pa.)
}

(Submitted for publication July 9, 1958; accepted August 13, 1958)

Human blood contains an inactive proteolytic enzyme, plasminogen, which may be converted in vitro to its active form, plasmin, either spontaneously or by the addition of various agents (1). A similar activation is believed to occur in vivo after exposure to a variety of noxious circumstances $(2-6)$. Since plasmin catalyzes the hydrolysis of corticotropin A (7), it is possible that circumstances which induce the activation of plasmin will result also in an increase in the rate of destruction of adrenocorticotropic (ACTH) and other polypeptide hormones.

The present study was designed to determine the in vitro hydrolytic action of human blood

* Aided by grants from the National Institutes of Health, United States Public Health Service (A-1409), and Merck and Company, Inc. plasma on $\mathrm{ACTH}$, somatotropin, glucagon and insulin before and after the conversion of plasminogen to plasmin by streptokinase.

\section{METHODS}

Human blood plasma prepared from freshly drawn heparinized venous blood, plasminogen prepared from fresh plasma by Milstone's procedure (8), and two different preparations of plasmin $(9,10)$ were employed in this study. A preparation of streptokinase (SK) which contained approximately 4,000 units per mg. was used to activate the conversion of plasminogen to plasmin. Crystalline glucagon (molecular weight $[\mathrm{M} . \mathrm{W}]=4,$.000 ), a preparation of ACTH which assayed 5.3 units per $\mathrm{mg}$. (assumed M. W. $=10,000$ ), glucagon-free insulin (assumed M. W. $=12,000)$ and a preparation of somatotropin (assumed M. W. $=46,800$ ) were used as substrates. Substrates labeled with $\mathrm{I}^{181}$ by the method described by Bauman, Rothschild, Yalow and Berson (11) were used as tracers in a mixture with unlabeled substrate.

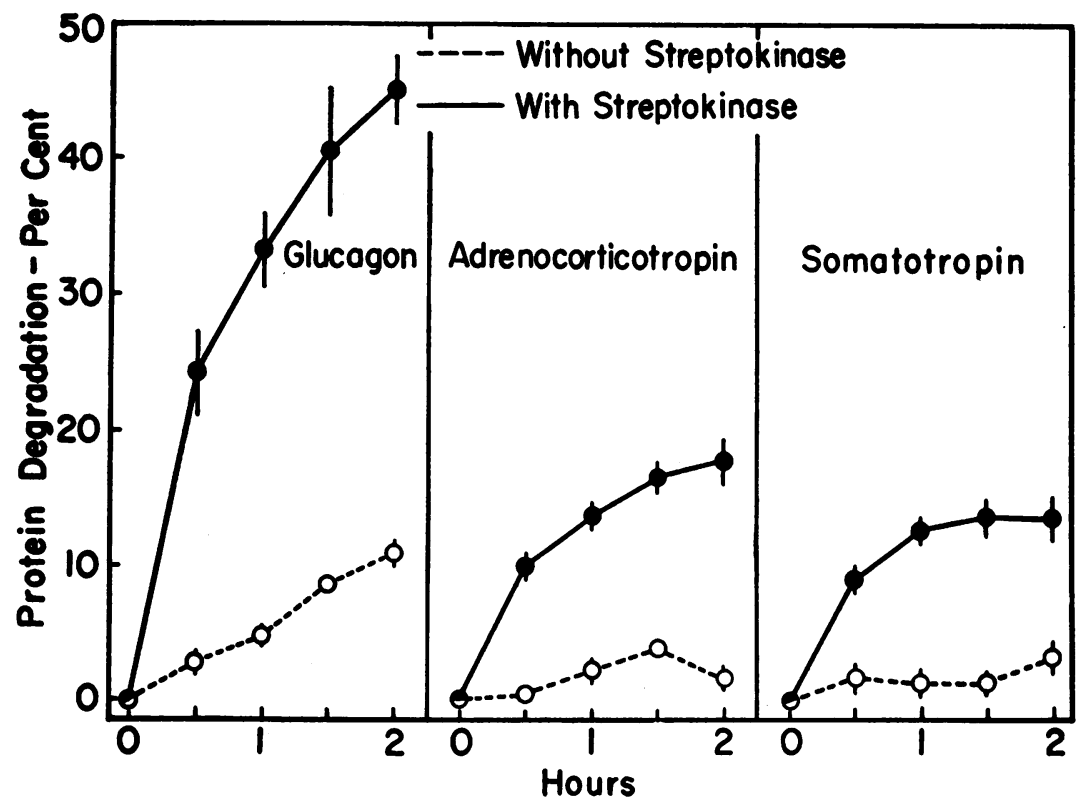

Fig. 1. The Degradation of Glucagon, Adrenocorticotropin and Somatotropin by Native Plasma and by Streptokinase-Activated Plasma

The per cent (mean plus or minus standard error) degraded at each interval was computed as indicated in text. 


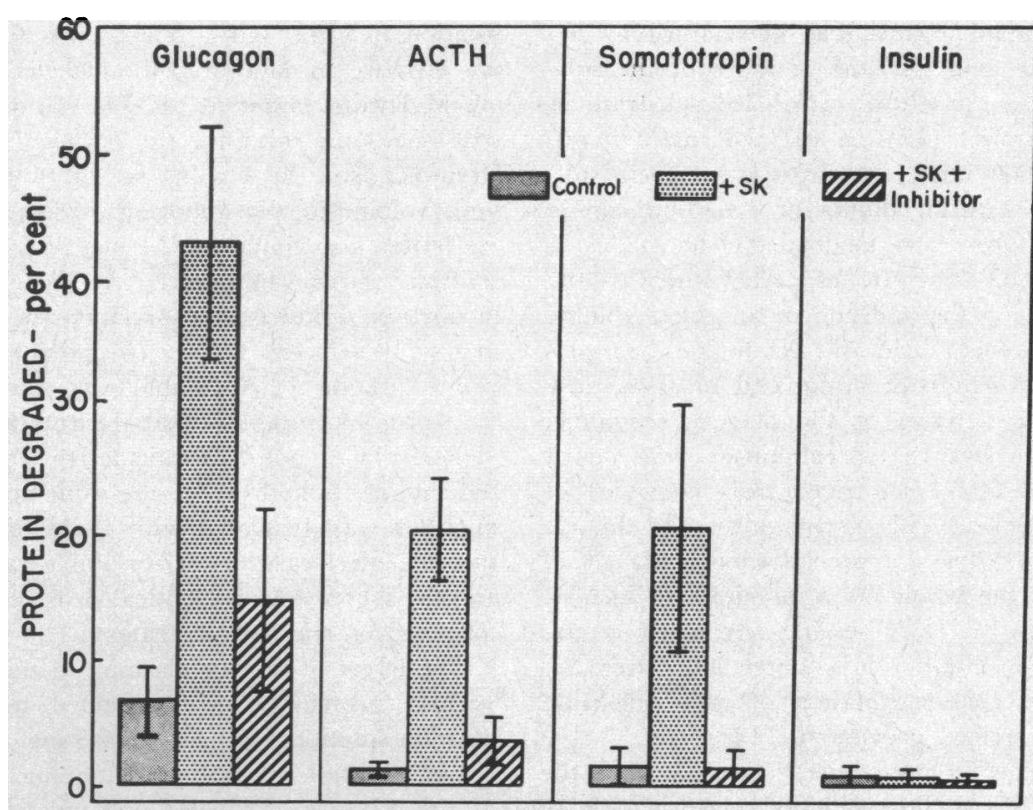

Fig. 2. The Degradation of Glucagon, Adrenocorticotropin, Somatotropin and Insulin by Crude Plasminogen, Streptokinase-Activated Plasminogen and Streptokinase-Activated Plasminogen in the Presence of Crystalline Soybean Trypsin Inhibitor

The per cent (mean plus or minus standard error) degraded during a 90 minute period of incubation was computed as indicated in text.

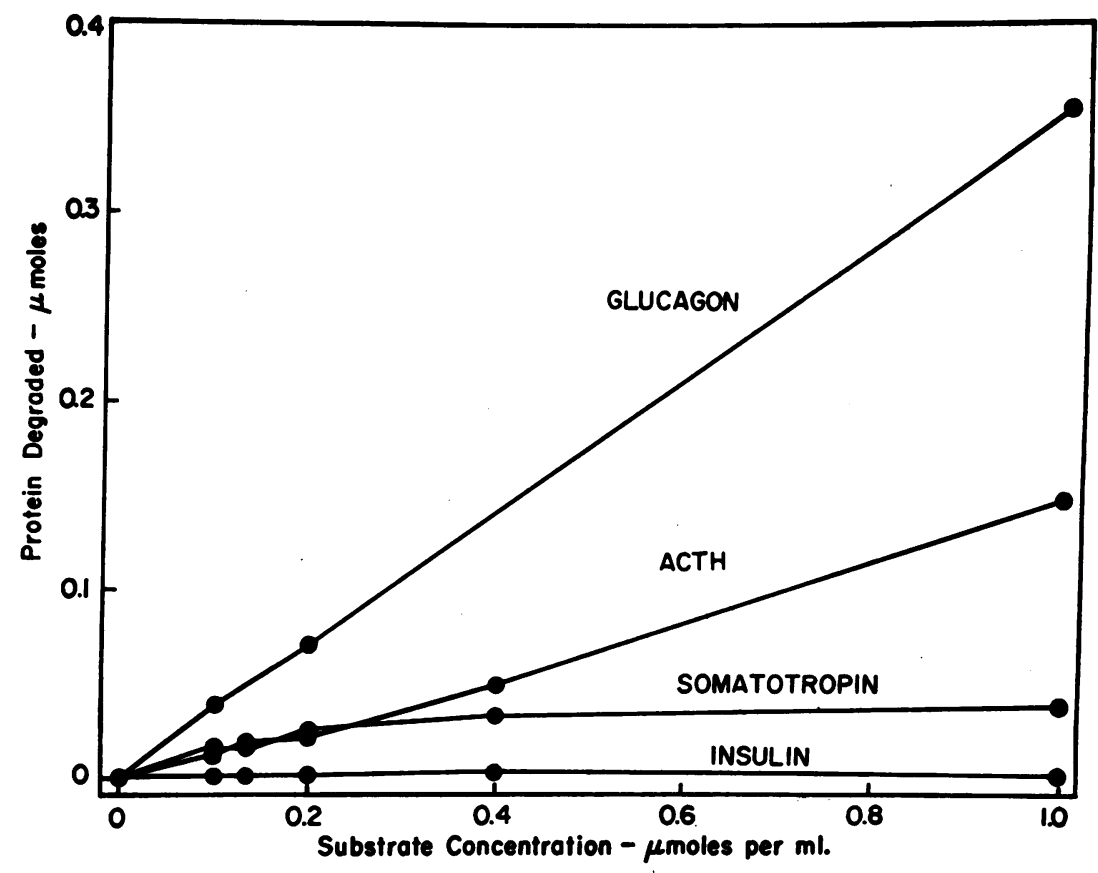

Fig. 3. Degradation of Various Concentrations of Glucagon, Adrenocorticotropin, Somatotropin and Insulin by Streptokinase-Activated Plasminogen

The quantity of protein degraded was computed from the TCA soluble radioactivity after incubation for 60 minutes at $37^{\circ} \mathrm{C}$. 
The activity of human plasma was determined by incubating $1 \mathrm{ml}$. plasma with $0.2 \mu \mathrm{M}$ or more of the substrate containing tracer quantities of labeled substrate in. $0.5 \mathrm{ml}$. McIlvaine buffer (12) at $\mathrm{pH} 7.8$ and $0.5 \mathrm{ml}$. buffer containing 1,000 units streptokinase. Each substrate was incubated with an aliquot of the same sample of plasma. The mixtures were incubated in test tubes in a Dubnoff shaker at $37^{\circ} \mathrm{C}$. At designated intervals the reaction was stopped by the addition of an equal volume of 10 per cent trichloracetic acid (TCA) to the appropriate tubes. One set of controls, designated to assess any preformed proteolytic activity of the plasma, contained plasma and substrate but the streptokinase was added after the TCA. A second set of controls consisted of incubation of the substrate with streptokinase and the addition of the plasma after the precipitation with TCA. The radioactivity of the whole TCA precipitated incubation mixture and of the TCA soluble portion were assayed in a well-type scintillation counter and after appropriate corrections the degradation of each substrate was computed as described previously (13).

Crude plasminogen was prepared by precipitating the euglobin fraction of fresh human blood plasma with 19 volumes of distilled water and adjusting to $\mathrm{pH} 5.2$ with 0.5 per cent acetic acid. The mixture was centrifuged and the precipitate from two volumes plasma was resuspended in one volume of McIlvaine's buffer. Each incubation mixture consisted of $1 \mathrm{ml}$. of the euglobulin solution, $0.5 \mathrm{ml}$. buffer containing $0.2 \mu \mathrm{M}$ or more of the mixture of labeled and unlabeled substrate, and 0.5 $\mathrm{ml}$. McIlvaine buffer at $\mathrm{pH} 7.8$. In a second set of tubes with the same mixture, the buffer contained 1,000 units streptokinase. In a third set of tubes consisting of the same volumes of plasminogen, substrate and streptokinase, the buffer also contained $2.4 \mathrm{mg}$. of five times crystallized soybean trypsin inhibitor. At designated intervals the incubation mixture was precipitated with an equal volume of 10 per cent TCA. The proportion of the substrate which became TCA soluble was determined as above.

In order to establish that the rate at which a substrate yielded TCA soluble radioactive fragments represents the rate of its hydrolysis, the same concentration of plasminogen was incubated with $1 \mu \mathrm{M}$ of each substrate and the rate of release of TCA soluble radioactive fragments and the increase in the optical density at $280 \mathrm{~m} \mu$ were determined on the same filtrates.

The effect of human plasmin on the degradation of the various proteins was determined by incubating $1 \mathrm{ml}$. plasmin solution (from 0.2 to $0.5 \mathrm{mg}$. in $1 \mathrm{ml}$. McIlvaine's buffer) with $1 \mathrm{ml}$. buffer containing from 0.1 to $1.0 \mu \mathrm{M}$ of the mixture of labeled and unlabeled substrate.

\section{RESULTS}

Incubation of fresh native plasma (final concentration, $0.5 \mathrm{ml}$. per $\mathrm{ml}$. incubation mixture)

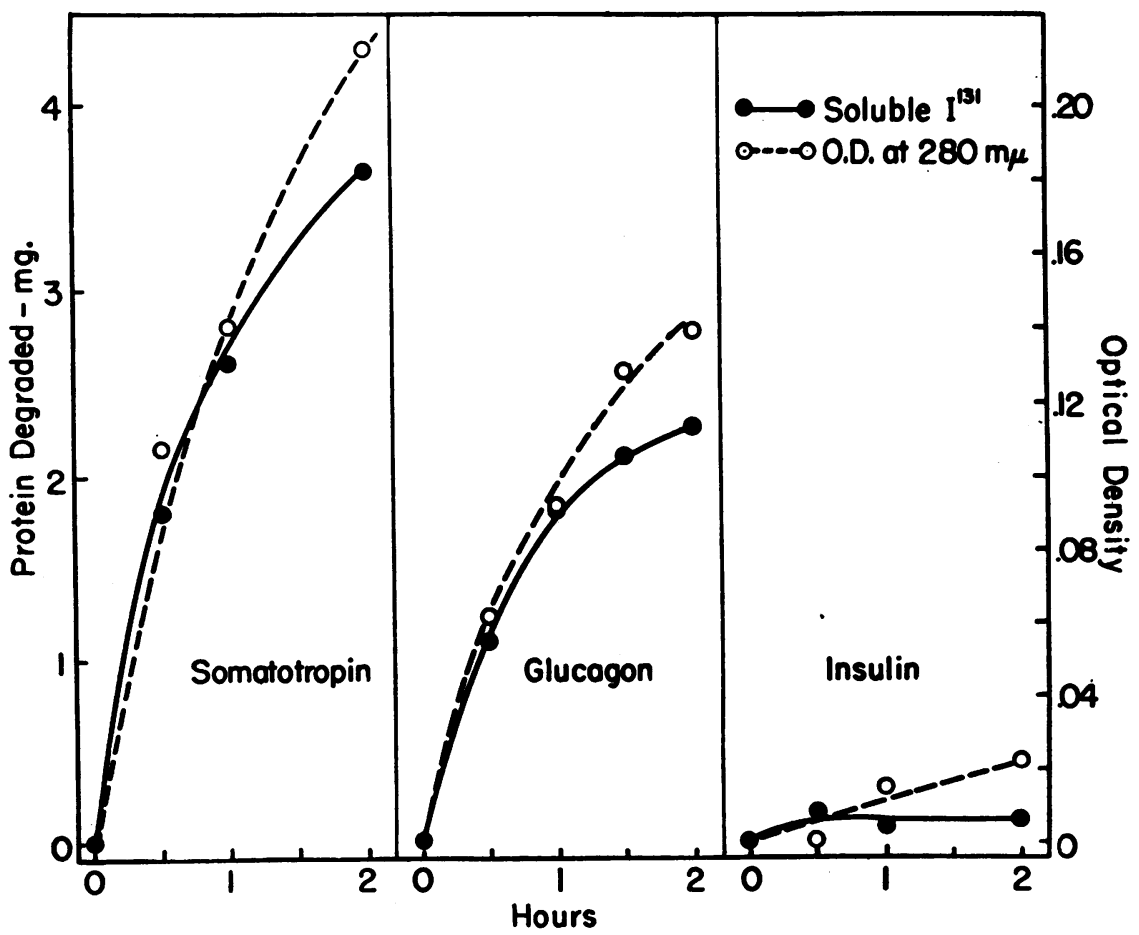

Fig. 4. Degradation of Glucagon, Adrenocorticotropin and Somatotropin by Streptokinase-Activated Crude Plasminogen as Measured by the Increase in TCA Soluble Radioactive Fragments and the Optical Density at 280 м $\mu$

The quantity of protein degraded was computed as indicated in text. 

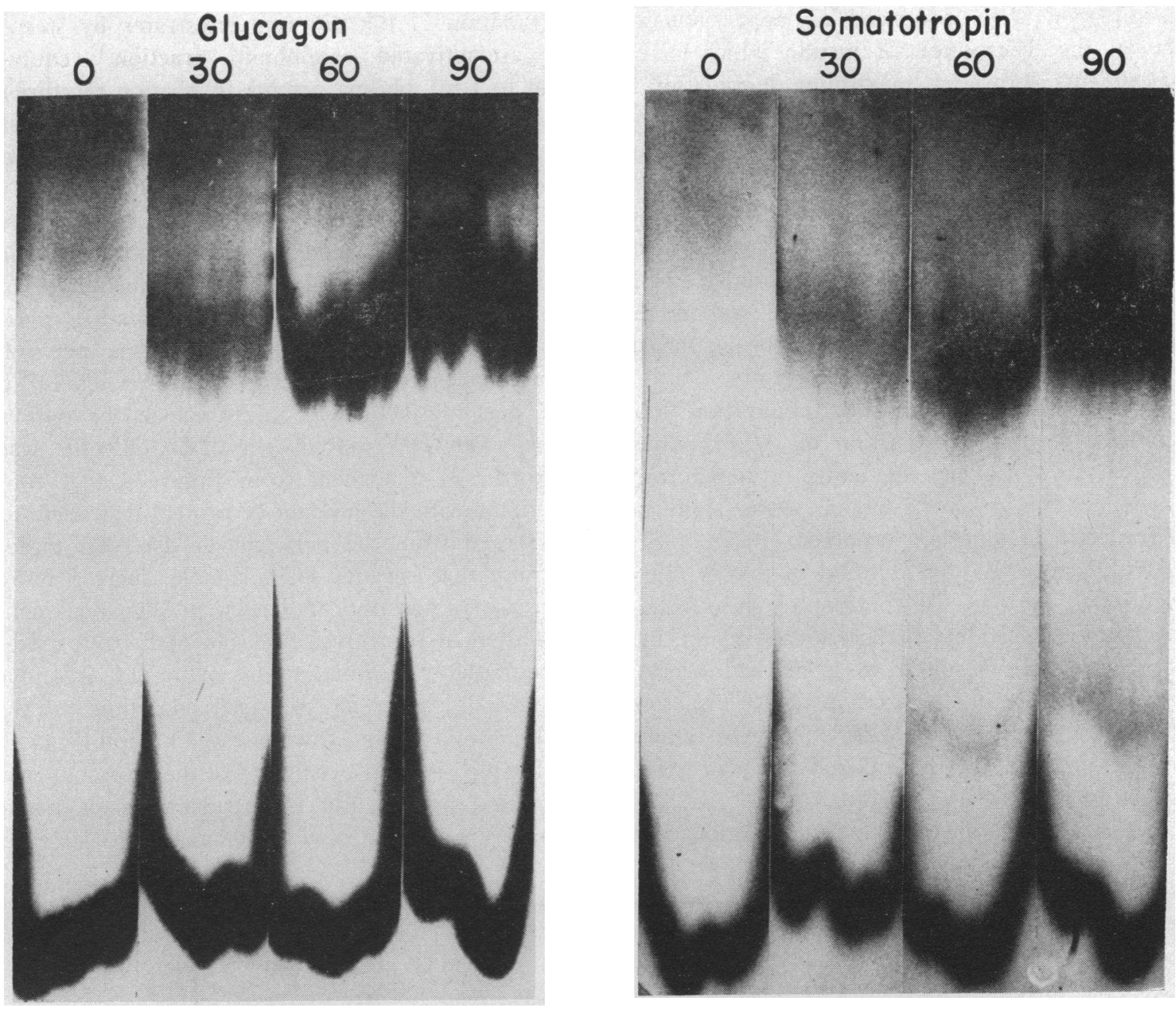

Fig. 5. Degradation of Glucagon and of Somatotropin by Streptokinase-Activated Plasma

Radioautographs of descending chromatograms of aliquots $(100 \lambda)$ of incubation mixtures removed at designated intervals, streaked on paper and chromatographed as indicated in text. The radioautographs were cut just below the point at which the aliquots were streaked.

with insulin (final concentration, $0.1 \mu \mathrm{M}$ per $\mathrm{ml}$. incubation mixture) produced an insignificant effect on the degradation of insulin during the two hour incubation period. The maximum change that was found with nine different samples of plasma was 0.9 per cent which is well within the error of the procedure; the mean plus or minus standard error was $0.3 \pm 0.4$ per cent. Of questionable significance also was the effect of the same concentration of native plasma on the degradation of ACTH and somatotropin (Figure 1). A more significant rate of degradation, however, occurred when glucagon was incubated with samples of the same native plasma.

Incubation with streptokinase alone produced no degradation of the four hormones. In the presence of both plasma and streptokinase there was a marked increase in the rate at which $\mathrm{ACTH}$, somatotropin and especially glucagon were degraded (Figure 1). The degradation of insulin, however, was not influenced appreciably, the maximum increase at the end of two hours being only 1.4 per cent with a mean plus or minus standard error of $0.6 \pm 0.5$ per cent.

The effect of the incubation of the various proteins (final concentration, $0.1 \mu \mathrm{M}$ per $\mathrm{ml}$. incubation mixture) with plasminogen alone (final concentration equivalent to $1 \mathrm{ml}$. plasma per $\mathrm{ml}$. incubation mixture) and with plasminogen plus streptokinase is illustrated in Figure 2. 
Plasminogen alone produced no appreciable effect on the destruction of insulin which in six experiments showed a maximum degradation of 1.3 per cent (mean \pm S.E., $0.9 \pm 0.8$ per cent) at the end of the 90 minute incubation period. The presence of streptokinase did not influence the effect of the action of plasminogen on insulin. Even with a 10 -fold increase in the concentration of plasminogen or with a prolongation of the incubation period to 72 hours there was no appreciable increase in the quantity of insulin destroyed over that obtained in two hours.

Whereas the plasminogen preparation alone produced a slight destruction of ACTH (mean \pm S.E., $1.7 \pm 1.6$ per cent) and of somatotropin (mean \pm S.E., $1.7 \pm 1.6$ ), a more significant degradation of glucagon occurred (mean \pm S.E., $6.7 \pm 2.7$ per cent) by the end of the 90 minute incubation period. In contrast to the effect on insulin, the addition of streptokinase to the incubation mixture resulted in a marked acceleration in the rate of degradation of $\mathrm{ACTH}$, somatotropin and glucagon. This effect was inhibited in the presence of crystallized soybean trypsin inhibitor (Figure 2).

The effect of varying the concentration on the degradation of the different substrates by streptokinase-activated euglobulin fraction (equivalent to $1 \mathrm{ml}$. plasma per ml. incubation mixture) is illustrated in Figure 3. It is apparent that at all concentrations tested, the rate of degradation of each hormone remained essentially constant.

In order to establish that the increase in the TCA soluble radioactive fragments is due to the hydrolysis of the labeled proteins, the effect of the incubation of streptokinase-activated plasminogen (equivalent to $1 \mathrm{ml}$. plasma per $\mathrm{ml}$. incubation mixture) with the various proteins (1.0 $\mu \mathrm{M}$ per ml. incubation mixture) on the optical density at $280 \mathrm{~m} \mu$ of the TCA filtrate was studied. It is evident from Figure 4 that concomitant with the amount of protein degraded, as calculated from the per cent of the total radioactivity that became TCA soluble, there was an increase in the optical density. Additional confirmation of proteolysis was obtained from radioautographs of chromatograms of the TCA soluble fraction (Figure 5) prepared according to the technique of Tong, Taurog and Chaikoff (14).

Purified human plasmin, like the streptokinaseactivated plasma and the streptokinase-activated plasminogen, produced no appreciable destruc-

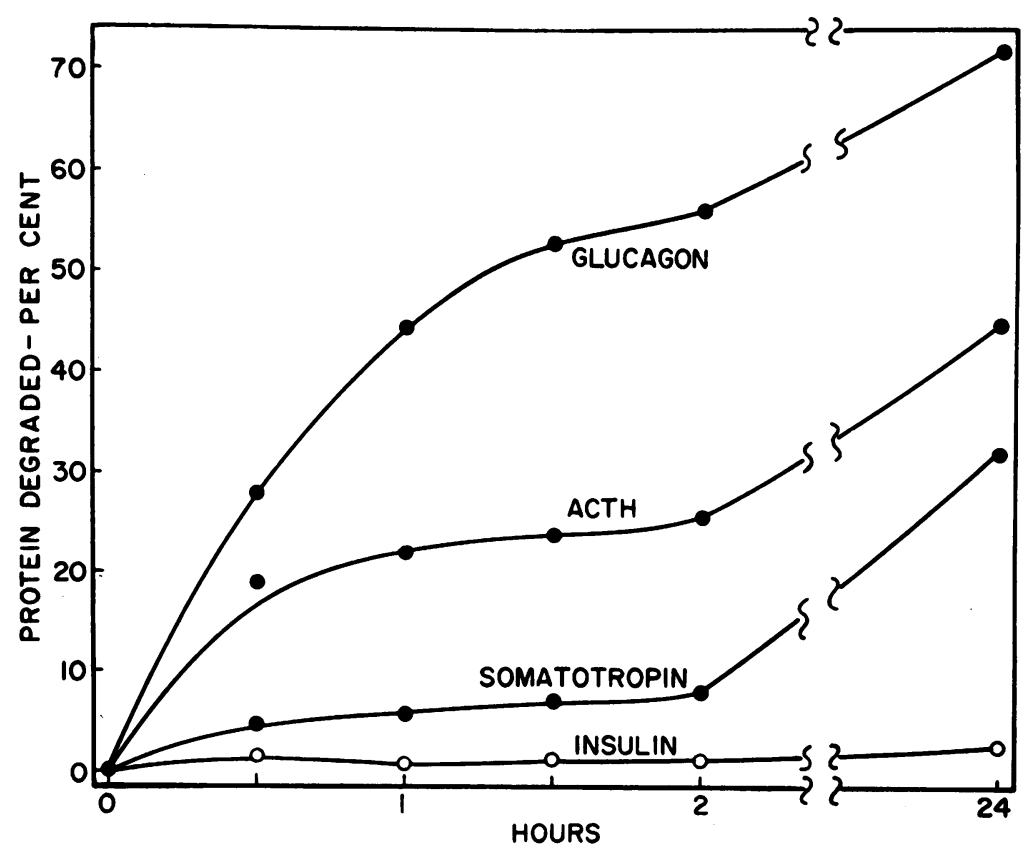

Fig. 6. Degradation of Insulin, Glucagon, Adrenocorticotropin and Somatotropin by Purified Human Plasmin

The per cent degraded at each interval was computed as indicated in text. 
tion of insulin even after incubation for 24 hours. Glucagon and ACTH, however, were rapidly destroyed by the plasmin while somatotropin was destroyed at a slower rate. Typical of the data obtained with the two preparations of purified plasmin used in this study are the data illustrated in Figure 6.

\section{DISCUSSION}

The data reported herein reveal that insulin is not degraded in vitro by native human plasma, streptokinase-activated plasma, streptokinase-activated plasminogen or purified human plasmin. Glucagon, ACTH and somatotropin, however, are hydrolyzed to some degree by native plasma and at a much greater rate by streptokinase-activated plasma, streptokinase-activated plasminogen and plasmin. The relatively low rate of destruction produced by native plasma does not contradict the conclusions of Reiss, Badrick, Halkerston and Plaice (15) and of Pincus, Hopkins and Hechter (16) that ACTH is inactivated by human plasma. Thus, Pincus and co-workers found that about 90 per cent of the activity of $\mathrm{ACTH}$ is destroyed after one hour incubation of 0.002 to 0.004 International unit per $\mathrm{ml}$. of human plasma. This rate of inactivation is within the range of the degradation observed herein since the incubation of approximately five units ACTH with $0.5 \mathrm{ml}$. plasma for two hours resulted in the degradation of the equivalent of from 0.1 to 0.2 unit.

The conversion of plasminogen to plasmin by streptokinase appears to be relatively specific to human blood (1) in that the plasminogen in native human plasma is readily activated by amounts of streptokinase which are without effect on the plasma of many subhuman species (17). This relative specificity is believed to be due to a "proactivator" which is presumed to be present in large concentrations only in human plasma $(1,18,19)$. Accordingly, the destruction of glucagon, ACTH and somatotropin by streptokinase-activated human plasma and streptokinaseactivated plasminogen may be due to the resultant plasmin as proposed by White and Gross as the mechanism responsible for the destruction of ACTH by plasma (7). In accord is the inhibitory action of crystallized soybean trypsin inhibitor on streptokinase-activated plasminogen.
The relatively low activity of native plasma may be attributed to the spontaneous conversion of some plasminogen to plasmin during the process of drawing the blood and separating the plasma.

The fact that the hydrolytic activity of the streptokinase-activated plasma was not completely inhibited by the quantities of soybean trypsin inhibitor used herein suggests that either the glucagon was not stable under the conditions of the assay or that some other proteolytic enzyme is also present in the plasma. It is pertinent to note, however, that even though a complete inhibition of proteolysis can be produced with larger quantities of soybean inhibitor, the possibility that another proteolytic system is also present is not eliminated because of the fact that soybean trypsin inhibitor is not very specific in its inhibition of proteolytic enzymes.

Plasmin has been shown to hydrolyze synthetic substrates such as arginine and lysine esters (20). The same apparent specificity is suggested by its action on corticotropin A (7) which is split after arginine in the sequence

$$
-\underset{8}{\text { Arg. Try. }} 9 .--
$$

and after lysine in the sequence

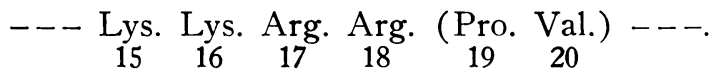

Plasmin, however, did not hydrolyze the bond after lysine in position 21

$$
\text { (-- Lys. Val. ---) }
$$

which may reflect a specificity requirement involving the amino-bearing residue of the bond attacked and also explain the failure to hydrolyze the linkage after arginine in position 18. If plasmin has the same type of action on other peptide hormones, then glucagon, the structure of which has been described by Bromer, Sinn, Staub and Behrens (21), may be split after lysine in the sequence

$$
\text { - } 12 \text { ys. Try. }---
$$

but not after arginine in the sequence

$$
--\underset{17}{\text { Arg. Arg. }--- \text {. }}
$$

Likewise, it could be anticipated that the B chain of insulin (22), if at all hydrolyzed, would split after arginine in the sequence

$$
-{ }_{22} \text { Arg. Gly. }{ }_{23}--
$$


or after lysine in the sequence

$$
--\underset{29}{29} 30
$$

and release at best only one $\mathrm{I}^{131}$ tagged tyrosine residue. The demonstration that insulin is not hydrolyzed by plasmin, however, suggests that the configuration of the intact molecule protects the aforementioned bonds.

As indicated at the outset, exposure to a variety of noxious stimuli may result in the conversion of plasminogen to plasmin in vivo. Accordingly, it may be postulated that such exposure may result in an increase in the rate of destruction of circulating glucagon, ACTH and somatotropin. Whether such an increase plays a significant role in the destruction of the various hormones by the intact organism remains unknown.

\section{SUMMARY}

Studies with native human plasma, the crude euglobulin fraction (plasminogen) of such plasma, streptokinase-activated plasma, streptokinase-activated plasminogen and purified human plasmin indicate that glucagon, adrenocorticotropin and somatotropin are very susceptible to hydrolysis by plasmin while insulin is resistant to such action.

\section{ACKNOWLEDGMENTS}

We are indebted to Dr. J. M. Ruegsegger (Lederle Medical Research Department, American Cyanamid Company) for a preparation of streptokinase (Varidase ${ }^{\circledR}$ ); to Dr. D. L. Kline and Dr. Sol Sherry for samples of purified human plasmin; to Dr. W. R. Kirtley (Eli Lilly and Company) for generous supplies of glucagon and glucagon-free insulin, and to The Endocrinology Study Section, National Institutes of Health for growth hormone (NIH-BGH-1).

\section{REFERENCES}

1. Astrup, T. Fibrinolysis in the organism. Blood 1956, 11, 781.

2. Biggs, R., Macfarlane, R. G., and Pilling, J. Observations on fibrinolysis; experimental activity produced by exercise or adrenaline. Lancet 1947, 1, 402.

3. Latner, A. L. Anxiety as a cause of fibrinolysis. Lancet 1947, 1, 194.

4. Tagnon, H. J., Levenson, S. M., Davidson, C. S., and Taylor, F. H. L. The occurrence of fibrinolysis in shock, with observations on the prothrombin time and the plasma fibrinogen during hemorrhagic shock. Amer. J. med. Sci. 1946, 211, 88.
5. Macfarlane, R. G., and Biggs, R. Fibrinolysis; its mechanism and significance. Blood 1948, 3, 1167.

6. Kwaan, H. C., and McFadzean, A. J. S. On plasma fibrinolytic activity induced by ischaemia. Clin. Sci. 1956, 15, 245.

7. White, W. F., and Gross, A. M. Studies on adrenocorticotropin. XIV. Action of bovine fibrinolysin and of liver cathepsin on corticotropin-A : Effect on biological activity. J. Amer. chem. Soc. 1957, 79, 1141.

8. Milstone, H. A factor in normal human blood which participates in streptococcal fibrinolysis. J. Immunol. 1941, 42, 109.

9. Kline, D. L. The purification and crystallization of plasminogen (profibrinolysin). J. biol. Chem. 1953, 204, 949.

10. Sherry, S., and Alkjaersig, N. Biochemical, experimental and clinical studies of proteolytic enzymes: With particular reference to the fibrinolytic enzyme of human plasma. Ann. N. Y. Acad. Sci. 1957, 68, 52.

11. Bauman, A., Rothschild, M. A., Yalow, R. S., and Berson, S. A. Distribution and metabolism of $\mathrm{I}^{181}$ labeled human serum albumin in congestive heart failure with and without proteinuria. J. clin. Invest. 1955, 34, 1359.

12. McIlvaine, T. C. A buffer solution for colorimetric comparison. J. biol. Chem. 1921, 49, 183.

13. Mirsky, I. A., Perisutti, G., and Dixon, F. J. The destruction of $\mathrm{I}^{131}$-labeled insulin by rat liver extracts. J. biol. Chem. 1955, 214, 397.

14. Tong, W., Taurog, A., and Chaikoff, I. L. Nonthyroglobulin iodine of the thyroid gland. I. Free thyroxine and diiodotyrosine. J. biol. Chem. 1951, 191, 665.

15. Reiss, M., Badrick, F. E., Halkerston, I. D. K., and Plaice, C. Inactivation of adrenotropic hormone (ACTH) by plasma. Nature 1951, 168, 206.

16. Pincus, G., Hopkins, T. F., and Hechter, O. An ACTH-inactivating factor in mammalian blood. Arch. Biochem. 1952, 37, 408.

17. Christensen, L. R. The streptokinase-plasminogen system in Streptococcal Infections, M. McCarty, Ed. New York, Columbia University Press, 1954, p. 39.

18. Sherry, S. The fibrinolytic activity of streptokinase activated human plasmin. J. clin. Invest. 1954, 33, 1054.

19. Müllertz, S. Activation of plasminogen. Ann. N. Y. Acad. Sci. 1957, 68, 38.

20. Troll, W., Sherry, S., and Wachman, J. The action of plasmin on synthetic substrates. J. biol. Chem. 1954, 208, 85.

21. Bromer, W. W., Sinn, L. G., Staub, A., and Behrens, O. K. The amino acid sequence of glucagon. Diabetes 1957, 6, 234.

22. Sanger, F. Fractionation of oxidase insulin. Biochem. J. 1949, 44, 126. 